\title{
Макєঠovıкá
}

Tóp. 9 (1969)

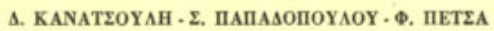

TOMOE ENATOE

1969

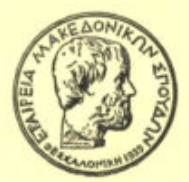

EN OEZIAAONIKH

1969

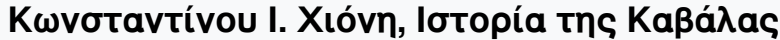

\section{A. Папаסорıаvós}

doi: $\underline{10.12681 / \text { makedonika.1056 }}$

\section{Copyright @ 2015, I. А. Папаסрıаvóc}

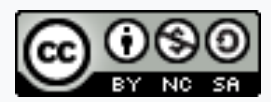

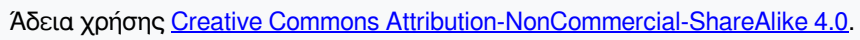

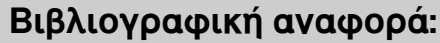

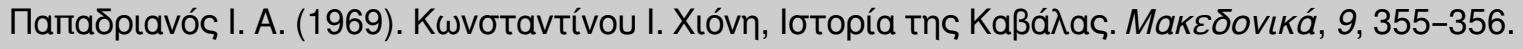

https://doi.org/10.12681/makedonika.1056 
$\varepsilon$ है

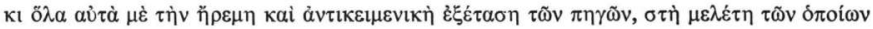

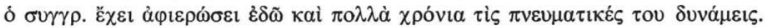

Z. N. TЕIPIAN $\Lambda H \Sigma$

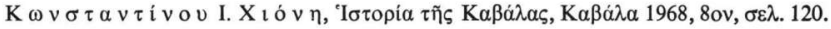

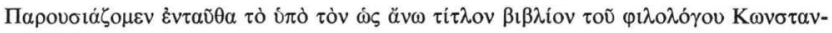

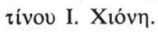

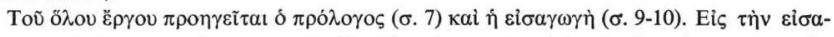

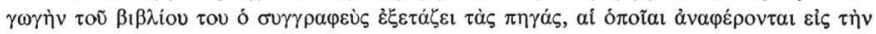
$\pi$ ó̀tv $\tau \tilde{n} \varsigma$ K $\alpha \beta a ́ \lambda \alpha \varsigma$.

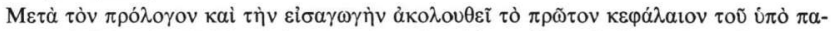

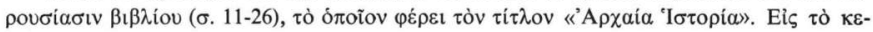

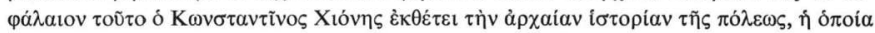

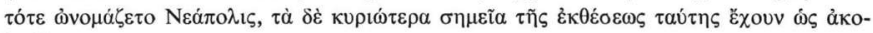
$\lambda$ oú $\theta \omega \varsigma$ :

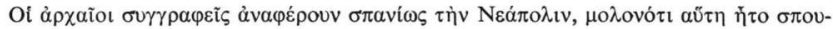

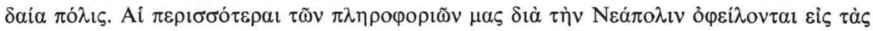

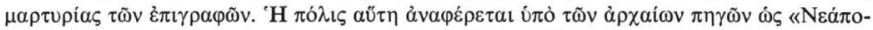

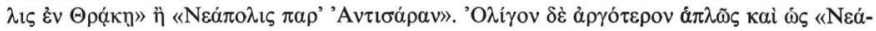
$\pi \mathrm{O} \lambda\left(\varsigma^{\prime}\right)$.

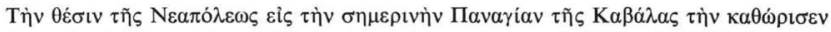

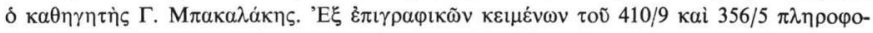

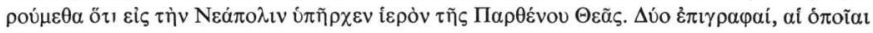

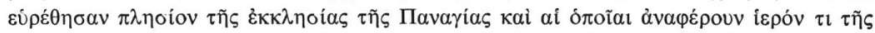

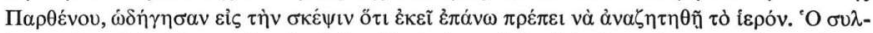

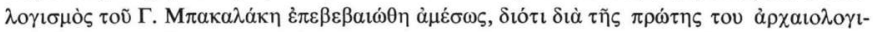

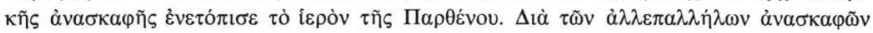

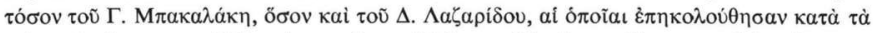

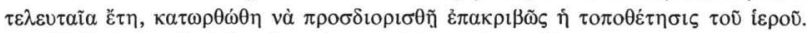

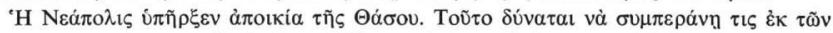

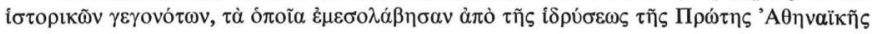

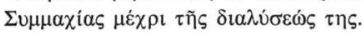

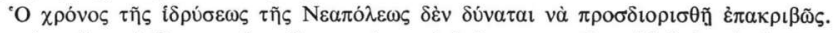

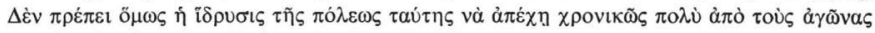

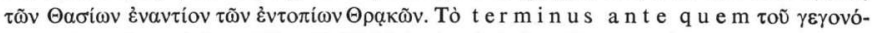

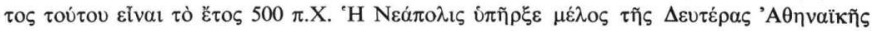

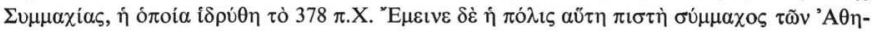

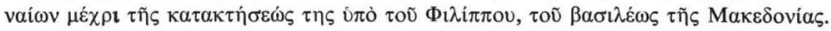

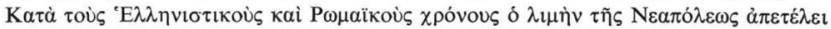

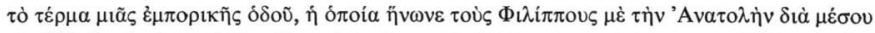

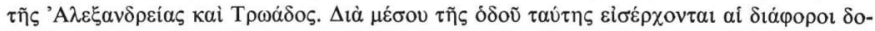

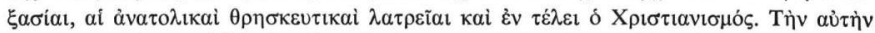

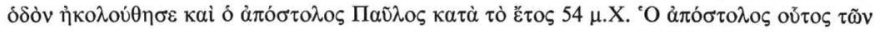

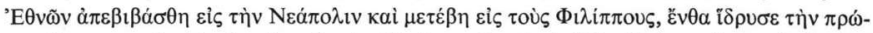
$\tau \eta \nu$ X

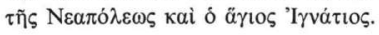




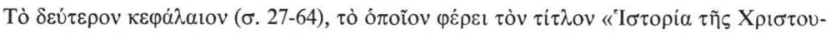

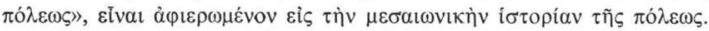

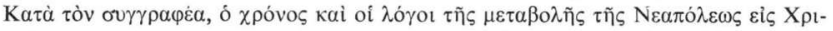

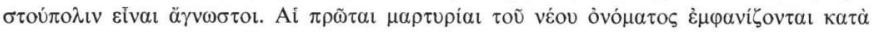

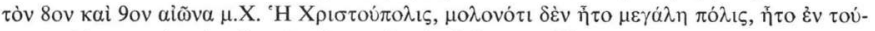

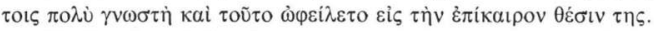

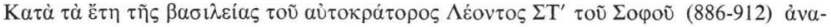

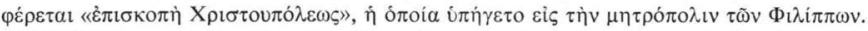

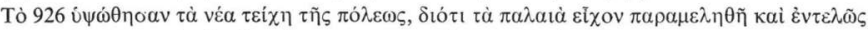

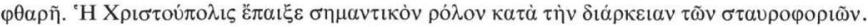

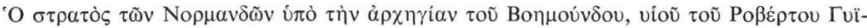

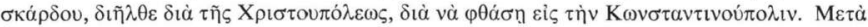

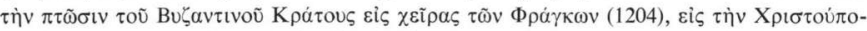

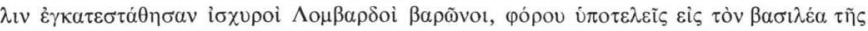

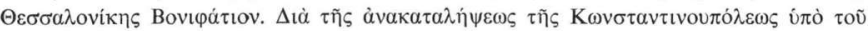

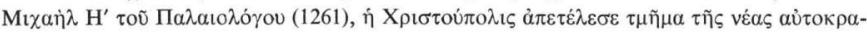
тopias.

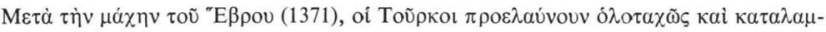

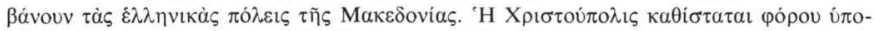

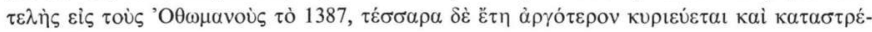


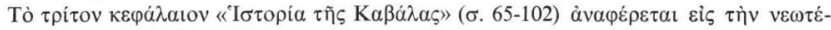

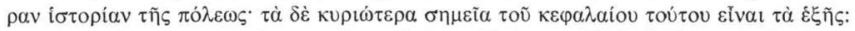

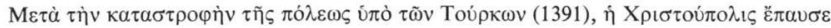

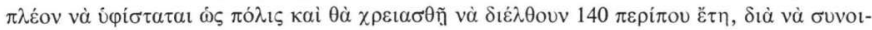

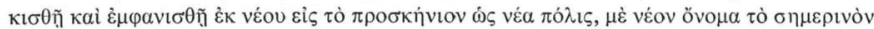

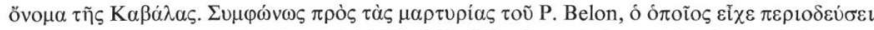

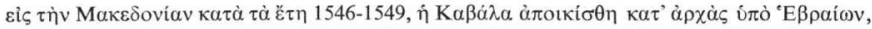

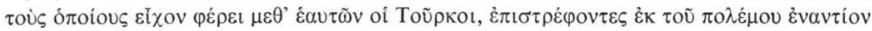

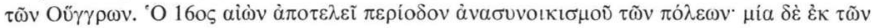

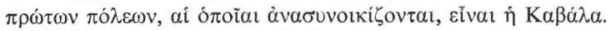

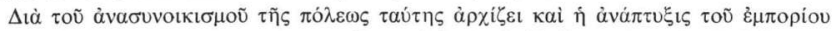

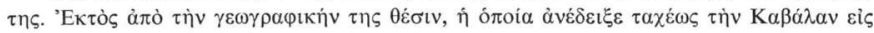

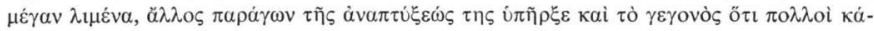

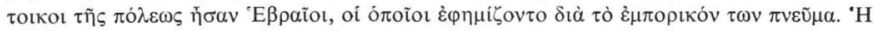

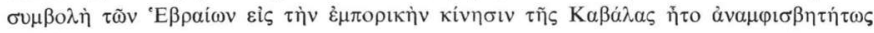
$\mu \varepsilon \gamma \alpha \dot{\alpha} \eta$.

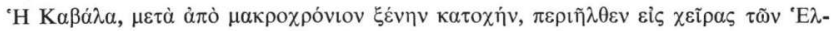

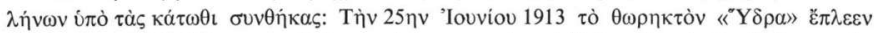

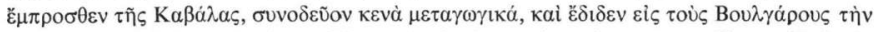

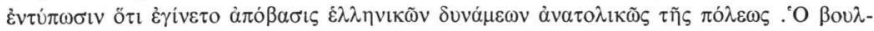

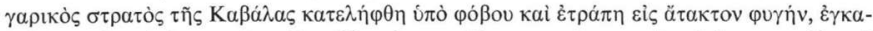

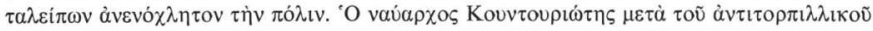

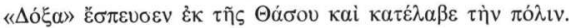

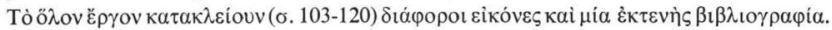

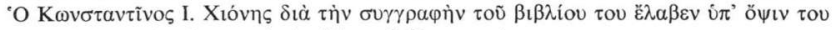

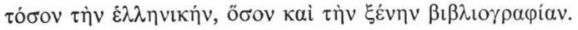

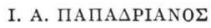

